\title{
Development of method for determining bottom-hole pressure in production wells
}

\author{
Vladislav I. Galkin \\ Department «Oil-and-gas geology» \\ Perm National Research Polytechnic University \\ Perm, Russia \\ vgalkin@pstu.ru
}

\author{
Inna N. Ponomareva \\ Department «Oil-and-gas technologies» \\ Perm National Research Polytechnic University \\ Perm, Russia \\ permpolitech@gmail.com
}

\author{
Irina A. Chernykh \\ Department Geophysical Geology Management \\ «LUKOIL-PERM» \\ Perm, Russia \\ irina.chernykh@1p.lukoil.com
}

\begin{abstract}
The paper is devoted to the effectiveness increase of monitoring the value of seam pressure when operating oilproducing wells. This problem is relevant for well operation when using subsurface measuring systems. In such cases, seam pressure is determined by recalculation of the dynamic level value, measured at wellhead. The absence of the method of reliable characterization of a multiphase flow leads to substantial errors in the seam pressure, measured in that way. In the present paper, a principally different approach to determination of seam pressure is considered, which is based on the mathematical processing of the accumulated data on parallel wellhead and subsurface measurements. Oil-producing wells, exploiting Famenskaya deposit of Ozyorny field, were chosen as an object of the research. The data on $\mathbf{5 7 9}$ parallel wellhead and subsurface measurements were processed. The use of incremental regression analysis made it possible to develop multidimensional models for Famenskaya deposit, allowing one to determine the seam pressure value in the absence of possibility of its direct measurement. A principle advantage of the developed method is the use of only those parameters as initial data, the determination of which during well operation is not accompanied by difficulties. Comparison of seam pressures, measured and calculated by means of the obtained models, demonstrates high reliability of the developed method.
\end{abstract}

Keywords - oil producing well; bottom-hole pressure; bottomhole pressure monitoring; multivariate mathematical models; correlation analysis; correlation number.

\section{INTRODUCTION}

An optimal method of bottom-hole pressure definition in oil wells is its direct measurement by subsurface pressure gages. Availability of the subsurface pump in a well makes gage running difficult. In these cases, definition of bottomhole pressure is provided by one of the following methods:

- direct measurement of pressure during pump suction using specially installed sensors; the pressure during pump suction is further recalculated into the bottomhole pressure without any problems;
- measurement of wellhead parameters of wells' operation (dynamic head $\mathrm{Hd}$, pressure at wellhead in annulus $\mathrm{P}_{\mathrm{wh}}$ ) and their further recalculation into the bottom-hole pressure. The determination of the bottom-hole pressure by this method is accompanied by significant difficulties, regarding mainly the necessity to calculate characteristics of multiphase flow in a wellbore [1-9]. However, in the cases when the well is unequipped with subsurface measuring systems, the above-mentioned approach is widely used.

Several thousands of producing wells on Perm region territory are unequipped with subsurface measuring systems and the issue of reliable determination of the bottom-hole pressure for them is rather relevant. Industry documents, currently in force, regulate the determination of the bottomhole pressure by recalculating wellhead parameters with preliminary calculation of multiphase flow characteristics. In practice, the abovementioned method often demonstrates unreliable results. That is why, development of a quite different method of bottom-hole pressure definition is advisable. The work [10] proposes the method of bottom-hole pressure definition, based on building of multidimensional statistical models, the input parameters of which are the parameters, definition of which does not cause troubles during wells' operation. The abovementioned method has demonstrated high efficiency, and as the result, the conclusion was made on reasonability to develop analogous approaches for other fields of the region as well. This paper is devoted to development of statistical models, allowing one to define bottom-hole pressure during operation of the wells, located at Ozyorny field of Famenskaya deposit.

\section{INITIAL DATA}

The key advantage of the above mentioned method is use of only those parameters as the initial data, definition of 
which does not cause significant troubles during wells' operation. The parameters chosen are as follows:

- $\quad$ dynamic head $\mathrm{H}_{\mathrm{d}}(\mathrm{m})$;

- $\quad$ pressure at wellhead in annulus $\mathrm{P}_{\mathrm{wh}}(\mathrm{MPa})$;

- water cuttings of well production $\mathrm{W}(\%)$,

- fluid flow rate $\mathrm{Q}_{\mathrm{fl}}\left(\mathrm{m}^{3} /\right.$ day),

- $\quad$ oil flow rate $\mathrm{Q}_{\text {oil }}(\mathrm{t} /$ day),

- well depth to water-oil contact $\left(\mathrm{H}_{\mathrm{w}-\mathrm{o} \text { cont }}\right)$;

- depth of pump running $\mathrm{H}_{\text {pump }}(\mathrm{m})$,

- pump submersion $\mathrm{H}_{\text {subm }}(\mathrm{m})$.

The initial data used are the results of 579 parallel wellhead and subsurface measurements, carried out in 22 wells.

\section{DEVELOPMENT OF STATISTICAL MODELS}

The first stage included studies on evaluation of the influence of dedicated parameter values during well operation on the bottom-hole pressure value. Between values $\mathrm{P}_{\mathrm{b}-\mathrm{h}}$ and the above mentioned parameters, correlation coefficients $r$ are calculated. It should be mentioned that not only coefficients between the parameters and values of the bottomhole pressure, but also reciprocal coefficients between the studied parameters were calculated. Correlation coefficient values are demonstrated in the correlation matrix (table 1). Analysis of $r$ coefficient values has revealed that the influence of the parameters on $\mathrm{P} b$-h changes within a wide range, from statistically significant negative to statistically significant positive. The values of $r$ vary from -0.57 to +0.55 .

For more detailed analysis, correlation fields are constructed between the actual bottomhole pressure and the well operation indices. The correlation field between the "bottom-hole pressure-dynamic head" is shown in Fig.1.

Having analyzed the correlation field, it is available to define the following tendency: while increasing the dynamic head values, the bottom-hole pressure value reduces according to the statistically significant dependence:

$\mathrm{P}_{\mathrm{b}-\mathrm{h}}^{\mathrm{M}}=5.171+0.1904 \mathrm{Hd}$

when $\mathrm{r}=-0.4, \mathrm{p}=0.0000$.

TABLE I CORRELATION MATRIX AMONG OPERATION PARAMETERS

\begin{tabular}{|c|c|c|c|c|c|}
\hline & $P_{b-h}$ & $\mathrm{H}_{\mathrm{d}}$ & $\mathrm{P}_{\mathrm{wh}}$ & W & $\mathrm{Q}_{\mathrm{fl}}$ \\
\hline$P_{b-h}$ & 1.00 & $-0.57 *$ & $0.16^{*}$ & 0.05 & -0.04 \\
\hline $\mathrm{H}_{\mathrm{d}}$ & & 1.00 & 0.04 & $0.24 *$ & $-0.21^{*}$ \\
\hline$P_{w h}$ & & & 1.00 & -0.03 & $0.15^{*}$ \\
\hline W & & & & 1.00 & $0.11 *$ \\
\hline $\mathrm{Q}_{\mathrm{fl}}$ & & & & & 1.00 \\
\hline $\mathrm{Q}_{\text {oil }}$ & & & & & \\
\hline $\mathrm{H}_{\mathrm{w}-\mathrm{o} \text { con }}$ & & & & & \\
\hline $\mathrm{H}_{\text {pump }}$ & & & & & \\
\hline $\mathrm{H}_{\text {subm }}$ & & & & & \\
\hline
\end{tabular}

TABLE I. CONTINUED

\begin{tabular}{|c|c|c|c|c|}
\hline & & & & \\
& $\mathrm{Q}_{\text {oil }}$ & $\mathrm{H}_{\mathrm{w}-\mathrm{oc}}$ & $\mathrm{H}_{\mathrm{pump}}$ & $\mathrm{H}_{\text {subm }}$ \\
\hline $\mathrm{P}_{\mathrm{b}-\mathrm{h}}$ & -0.05 & $0.44^{*}$ & 0.04 & $0.55^{*}$ \\
\hline $\mathrm{H}_{\mathrm{d}}$ & $-0.29 *$ & $-0.23^{*}$ & $-0.33^{*}$ & $-0.94^{*}$ \\
\hline $\mathrm{P}_{\mathrm{wh}}$ & $0.16^{*}$ & -0.02 & $0.28^{*}$ & -0.02 \\
\hline $\mathrm{W}$ & -0.08 & $-0.12^{*}$ & $-0.21^{*}$ & $-0.22^{*}$ \\
\hline $\mathrm{Q}_{\mathrm{fl}}$ & $0.95^{*}$ & -0.05 & $0.17^{*}$ & $0.27^{*}$ \\
\hline $\mathrm{Q}_{\mathrm{oil}}$ & 1.00 & $-0.09^{*}$ & $0.27^{*}$ & $0.34^{*}$ \\
\hline $\mathrm{H}_{\mathrm{w}-\mathrm{o} \text { cont }}$ & & 1.00 & $0.09^{*}$ & $0.25^{*}$ \\
\hline $\mathrm{H}_{\mathrm{pump}}$ & & & 1.00 & $0.48^{*}$ \\
\hline $\mathrm{H}_{\mathrm{subm}}$ & & & & 1.00 \\
\hline
\end{tabular}

It should be mentioned that when $H d<800 \mathrm{~m}$, the correlation between $\mathrm{H}_{\mathrm{d}}$ and $\mathrm{P}$ b-h is more weak than when $\mathrm{Hd}>800 \mathrm{~m}$.

According to this dependence, model values $\mathrm{P}_{\mathrm{b}-\mathrm{h}}{ }^{\mathrm{MHd}}$ are calculated and compared with actual values of the bottomhole pressure (Fig.2).

The correlation field between the "bottom-hole pressurepump submersion" is shown in Fig. 3. With increasing values of $\mathrm{H}_{\text {subm }}$, the value of $\mathrm{P}_{\mathrm{b}-\mathrm{h}}$ increases according to the following relationship:

$$
\mathrm{P}_{\mathrm{b}-\mathrm{h}}{ }^{\text {MHsubm }}=4.712+0.003695 \mathrm{H}_{\text {subm }}
$$

It should be noted that at $\mathrm{H}_{\text {subm }}<580 \mathrm{~m}$, the correlation between $\mathrm{H}_{\text {subm }}$ and $\mathrm{P}_{\mathrm{b}-\mathrm{h}}$ is stronger than for $\mathrm{H}_{\text {subm }}>580 \mathrm{~m}$. Based on this dependence, the predicted values of $\mathrm{P}_{\mathrm{b}-\mathrm{h}}$ MHsubm were calculated and compared with $\mathrm{P}_{\mathrm{b}-\mathrm{h}}$ (Fig. 4).

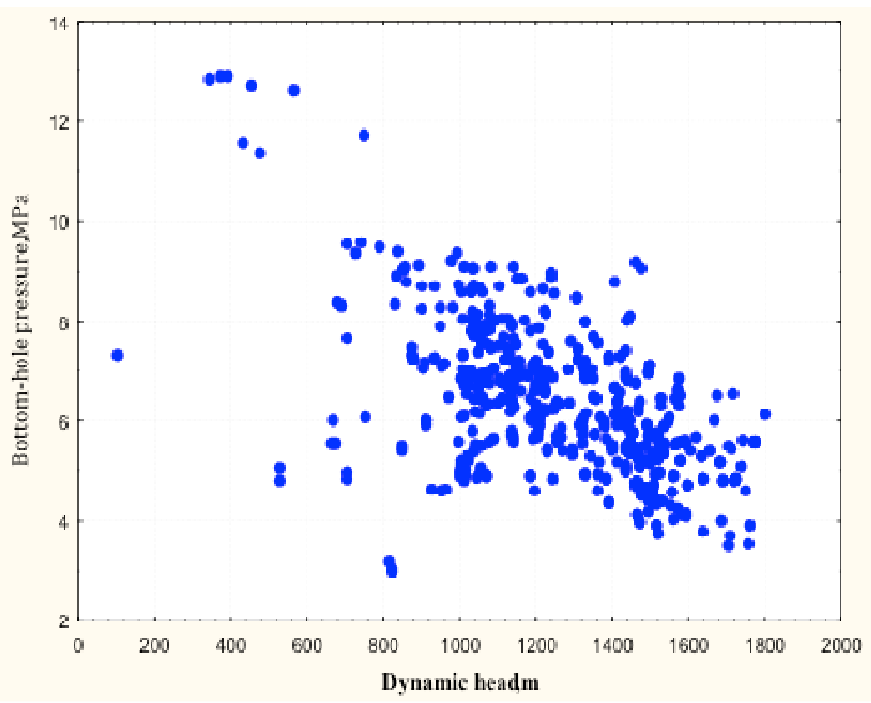

Fig. 1. Correlation field between parameters «Bottom-hole pressure dynamic head» 


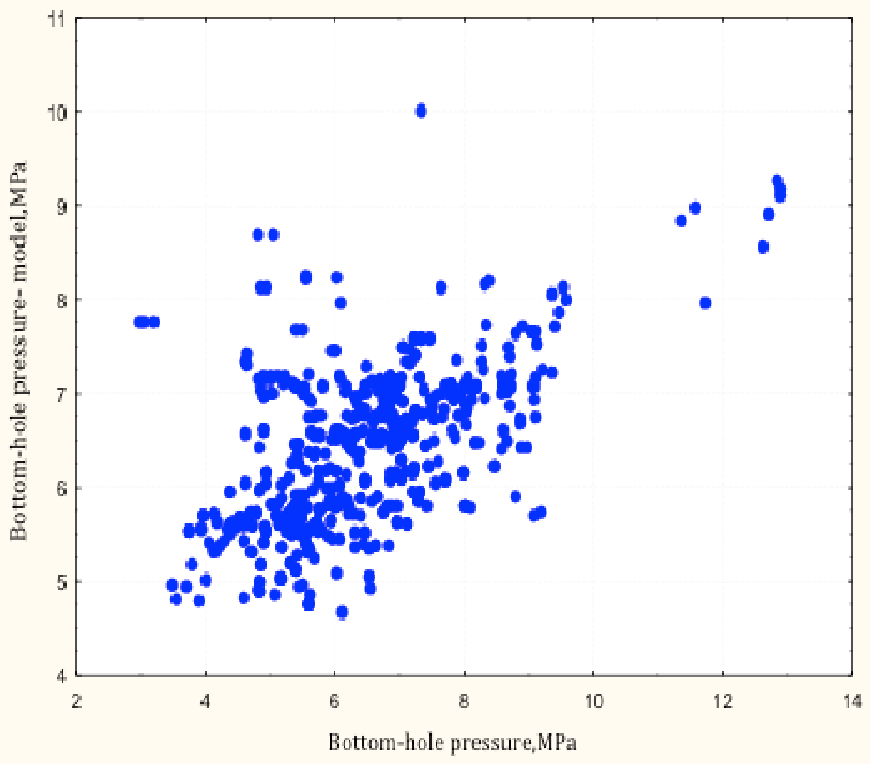

Fig.2. Correlation field between values $P_{b-h}$ and $P_{b-h}$ MHd

Figure 4 shows that these indicators strongly control each other.

That is why, taking into the account variety of different, in some cases, differently directed effects of the studied parameters by $\mathrm{P}_{\mathrm{b}-\mathrm{h}}$, let $\mathrm{us}$ build two versions of multidimensional models.

The first version - actual parameter values; the second version - actual parameter values, taking into the account time. Multidimensional models of these versions are built using incremental regression analysis (IRA) [11-13].

Calculation of regression coefficients of the developed model is provided using the least-squares method. Meanwhile, the $\mathrm{P}_{\mathrm{b}-\mathrm{h}}$ is a dependent criterion, and values $\mathrm{H}_{\mathrm{d}}, \mathrm{P}_{\mathrm{wh}}, \mathrm{W}, \mathrm{Q}_{\mathrm{fl}}$, $\mathrm{Q}_{\text {oil }}, \mathrm{H}_{\text {w-o cont }}, \mathrm{H}_{\text {pump }} \mathrm{H}_{\text {subm }}$ are independent factors, taking into account the versions used.

For the first version, the multidimensional model is as follows:

$\mathrm{P}_{\mathrm{b}-\mathrm{h}}^{\mathrm{MO}}=-941.156-0.001 \mathrm{H}_{\mathrm{d}}+0.520 \mathrm{H}_{\mathrm{w} \text {-ocont }}+0.022 \mathrm{~W}+$ $0.736 \mathrm{P}_{\mathrm{wh}}+0.007 \mathrm{Q}_{\text {oil }}-0.008 \mathrm{H}_{\text {pump }}+0.004 \mathrm{H}_{\text {subm }}-0.036 \mathrm{Q}_{\mathrm{fl}}$.

where $\mathrm{R}=0.779, \mathrm{p}<0.0000$, the standard error constitutes $0.92 \mathrm{MPa}$.

Generation of the model occurred in the succession, mentioned in the regression equation. Coefficient values, describing the force of statistical relations, changed as follows: $\mathrm{r}=0.567 ; \mathrm{R}=0.647,0.682,0.709,0.739,0.757,0.776,0.779$. This model was used to calculate values $\mathrm{P}_{\mathrm{b}-\mathrm{h}}$ MO for all the data which were compared with $\mathrm{P}_{\mathrm{b}-\mathrm{h}}$ (Fig.5).

Under the second version, the study of changes of $\mathrm{P}_{\mathrm{b}-\mathrm{h}}{ }^{\mathrm{M}}$ model values, depending on the studied parameters, is provided per data, sorted out by the time principle. For the given development object, the first model is built under three initial measurements $(n=3)$. The next model will be built when $\mathrm{n}=4$, and so on up to $\mathrm{n}=579$. Thus, 577 multidimensional models have been built. Examples of multidimensional models, taking into account the abovementioned principle, in increments of 50 values, are given in table 2 .
Analysis of all 577 models built reveals that parameter $\mathrm{H}_{\mathrm{d}}$ takes part in building of $553(95.8 \%)$ models; $\mathrm{P}_{\text {wh }}-$ in building of $574(99.5 \%), \mathrm{W}-514(89.1 \%), \mathrm{Q}_{\mathrm{fl}}-414(71.7 \%)$, $\mathrm{Q}_{\text {oil }}-424$ (73.5\%), $\mathrm{H}_{\text {w-o cont }}-566$ (98.1\%), $\mathrm{H}_{\text {pump }}-448$ $(77.6 \%), \mathrm{H}_{\text {subm }}-553(95.8 \%)$ models.

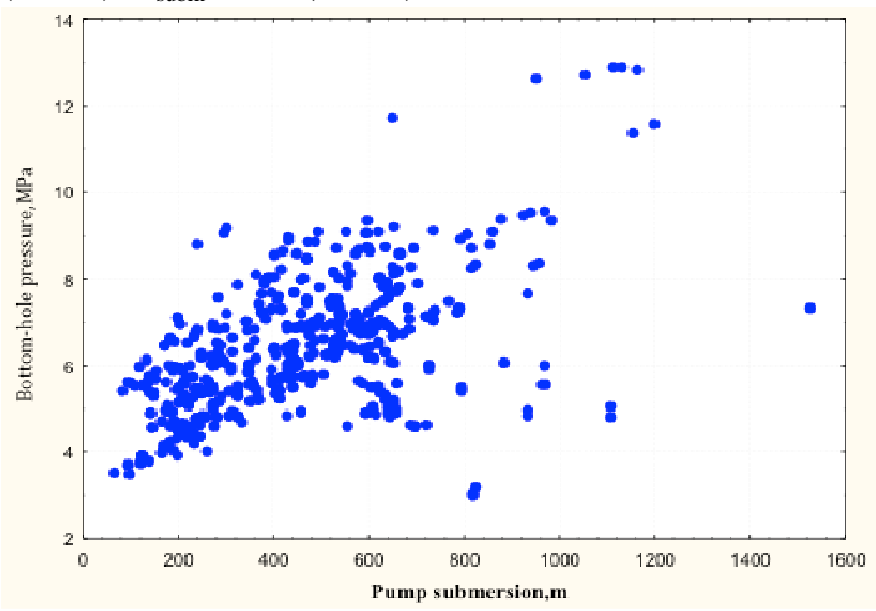

Fig.3. Correlation field between parameters "bottom-hole pressure pump submersion"

For more comprehensive analysis of time multidimensional models built, the change of absolute terms of the regression equation was compared to coefficients for parameters and $\mathrm{R}$ values in time. As an example, Fig. 6 shows the graph of the change in the coefficients of multiple correlation for the constructed multidimensional models.

Analysis of these charts has exhibited that in all the charts a significant change of values is revealed within the period till 05.04.2011; further, the tendency of values reduction is observed. To provide the limit of studied characteristics change, i.e. sample division into two classes regarding the time, linear discriminant analysis (LDA) was used.

As a result of applying this method, the following linear discriminant function is obtained:

$\mathrm{Z}=-0.021 \mathrm{~W}-0.730 \mathrm{H}_{\text {w-o cont }}-0.005 \mathrm{H}_{\mathrm{d}}-0.0012 \mathrm{H}_{\text {subm }}+0.620$ $\mathrm{P}_{\mathrm{wh}}-0.008 \mathrm{H}_{\mathrm{pump}}-0.092 \mathrm{Q}_{\mathrm{fl}}+0.095 \mathrm{Q}_{\mathrm{oil}}+1365.633$

where $\mathrm{R}=0.497, \chi^{2}=162.85$, $\mathrm{p}=0.000$.

For this function, the $\mathrm{Z}$ values for the entire sample were calculated and the probability values of belonging to the first class of $\mathrm{P}(\mathrm{Z})$ were determined. The relationship between $\mathrm{Z}$ and $P(Z)$ is shown in Fig.7.

It can be seen from the figure that as the values of $\mathrm{Z}$ are increased, the value of $P(Z)$ increases regularly. The average value of $Z$ for the first class is +0.335 , for the second --0.976 . The resulting class division was used in the construction of multidimensional models for predicting bottomhole pressure values.

The evaluation of the reliability of the division of the sample into classes is performed by methods of mathematical statistics (Table 3). The average values of the analyzed indicators are statistically different in six cases out of eight, which confirms the correctness of the division of the sample into two classes. 


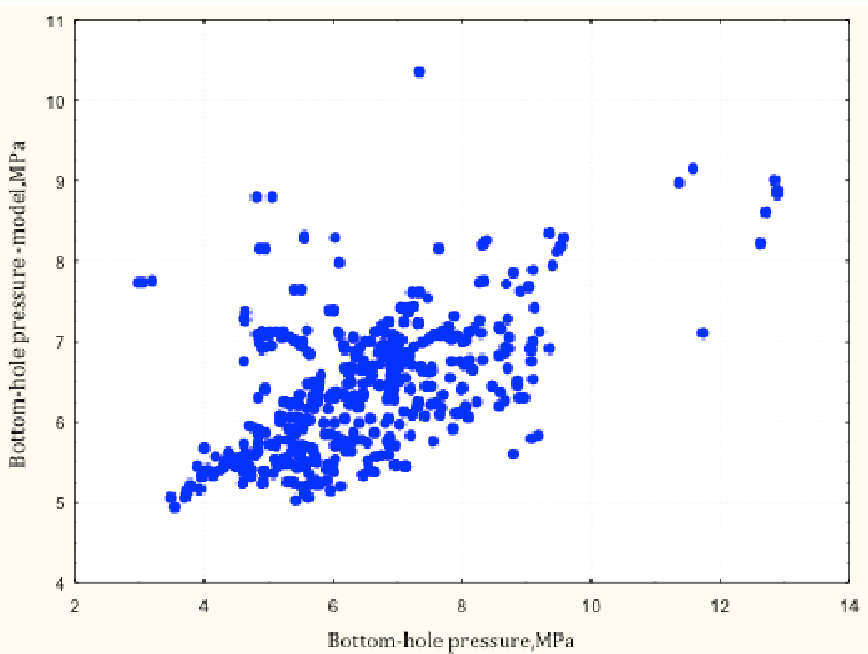

Fig.4. Correlation field between values $\mathrm{P}_{\mathrm{b}-\mathrm{h}}$ and $\mathrm{P}_{\mathrm{b}-\mathrm{h}}$ MHsubm

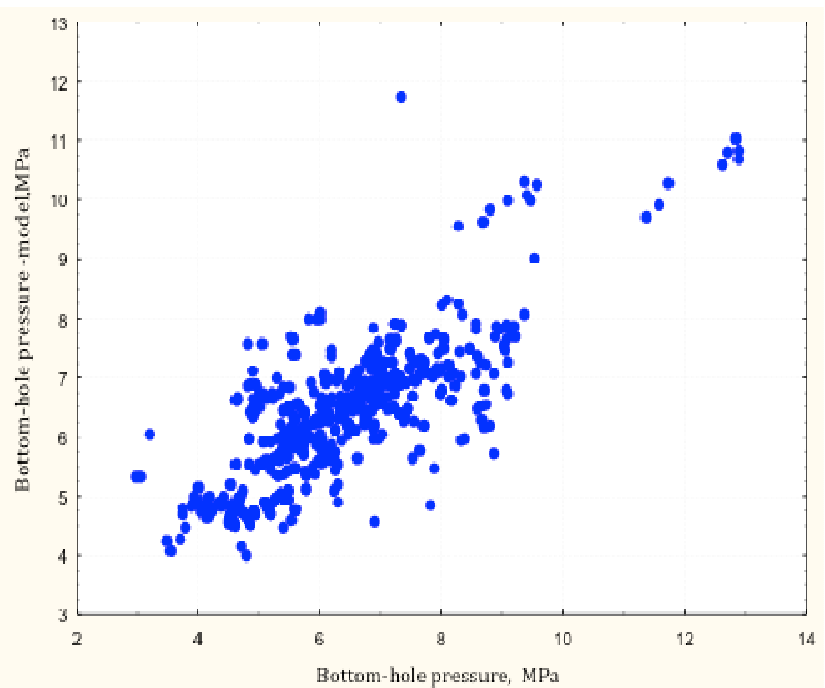

Fig.5. Correlation field between actual and model ( first version) values of bottom-hole pressure

TABLE II. MULTiDimENSIONAL MOdelS TO CALCULATE BOTTOM-HOLE PRESSURES AS PER SECOND VERSION $\left(\mathrm{P}_{\mathrm{B}-\mathrm{H}} \mathrm{MM}\right)$

\begin{tabular}{|c|c|c|c|c|}
\hline \multirow{2}{*}{$\mathrm{n}$} & \multirow{2}{*}{$\begin{array}{c}\text { Absolute term- } \\
\text {-numerator, p } \\
\text { value - } \\
\text { denominator }\end{array}$} & \multicolumn{3}{|c|}{$\begin{array}{c}\text { Coefficients for parameters - numerator, } \\
\text { p value - denominator }\end{array}$} \\
\hline & & $\mathrm{H}_{\mathrm{d}}$ & $\mathrm{P}_{\mathrm{wh}}$ & W \\
\hline 3 & $\frac{-784.129}{0.030301}$ & & & \\
\hline 50 & $\frac{-1243.29}{0.007083}$ & 0.0 .000000 & $\underline{0.000511}$ & \\
\hline 100 & $\frac{-1289.83}{0.007083}$ & 0.0 .000000 & $\underline{0.0193}$ & \\
\hline 150 & $\frac{-2970.34}{0.000000}$ & $0 . \frac{-0.01}{000017}$ & $\underline{0.0093}$ & $\underline{0.000000}$ \\
\hline 200 & $\frac{-3064.78}{0.000000}$ & 0.000000 & 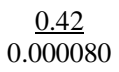 & $\underline{0.000000}$ \\
\hline 250 & $\frac{-3359.22}{0.000000}$ & $0 . \frac{-0.01}{000000}$ & $\underline{0.000080}$ & $\underline{0.10}$ \\
\hline
\end{tabular}

\begin{tabular}{|c|c|c|c|c|}
\hline 300 & $\frac{-3330.98}{0.000000}$ & $0 . \frac{-0.01}{000000}$ & $\frac{0.38}{0.000002}$ & $\underline{0.0000}$ \\
\hline 350 & $\frac{-3180.81}{0.000000}$ & $0 . \frac{-0.01}{0.00007}$ & $\frac{\underline{0.39}}{0.000006}$ & $\underline{0.000000}$ \\
\hline 400 & $\frac{-2833.41}{0.000000}$ & $\frac{\underline{-0.01}}{0.000007}$ & $\underline{0.000006}$ & $\underline{0.0004}$ \\
\hline 450 & $\frac{-2391.04}{0.000000}$ & $0 . \frac{-0.001}{0.083174}$ & $\underline{0.000000}$ & $\underline{0.0000}$ \\
\hline 500 & $\frac{-1340.79}{0.000000}$ & $\frac{0.000004}{0.994319}$ & $\underline{0.64}$ & $\underline{0.002}$ \\
\hline 550 & $\frac{-1030.35}{0.000000}$ & $\frac{-0.0003}{0.588411}$ & $\underline{0.71}$ & $\underline{0.000000}$ \\
\hline 579 & $\frac{-941.156}{0.000000}$ & $\frac{-0.001}{0.242098}$ & $0 . \underline{0.736}$ & $\frac{0.022}{0.000000}$ \\
\hline
\end{tabular}

TABLE II. CONTINUED

\begin{tabular}{|c|c|c|c|c|c|c|}
\hline \multirow{2}{*}{$n$} & \multicolumn{5}{|c|}{$\begin{array}{l}\text { Coefficients for parameters - numerator, } \\
\text { p value - denominator }\end{array}$} & \multirow{2}{*}{$\begin{array}{c}\mathrm{R}- \\
\text { numerator, } \\
\mathrm{p} \text { value- } \\
\text { denominator }\end{array}$} \\
\hline & $\mathrm{Q}_{\mathrm{fl}}$ & Qoil & $\mathrm{H}_{\mathrm{w}-\mathrm{o} \text { cont }}$ & $\mathrm{H}_{\text {pump }}$ & $\mathrm{H}_{\text {subm }}$ & \\
\hline 3 & & & & & & $\frac{0.991}{<0.1220}$ \\
\hline 50 & & $\underline{0.01}$ & $\underline{0.006859}$ & $\underline{0.002}$ & 0.000000 & $\frac{0.838}{<0.1158}$ \\
\hline 100 & & & $\underline{0.0015} 11$ & $\underline{0.000000}$ & 0.0 .000000 & $<0.0000000$ \\
\hline 150 & & $\underline{0.02}$ & $\underline{1.61}$ & $\underline{0.002499}$ & $\frac{-0.01}{0.006058}$ & $<0.000000$ \\
\hline 200 & 0.0 .32 & $\underline{0.041755}$ & $\underline{0.000000}$ & $\underline{0.001}$ & 0.0 .000064 & $<0.0000000$ \\
\hline 250 & 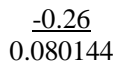 & $\underline{0.0673}$ & $\underline{0.000000}$ & $\underline{0.001}$ & 0.000840 & 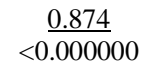 \\
\hline 300 & & & $\underline{1.81}$ & $\underline{0.001}$ & 0.0 .012 & $<0.0000000$ \\
\hline 350 & 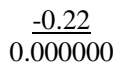 & $\underline{0.000000}$ & $\frac{1.73}{0.000000}$ & $\underline{0.195186}$ & $0 . \frac{-0.01}{060418}$ & $<\frac{0.8154}{<0.000000}$ \\
\hline 400 & $0 . \frac{-0.15}{000000}$ & $\underline{0.16}$ & $\underline{0.000000}$ & & $0 . \frac{-0.01}{109712}$ & 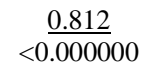 \\
\hline 450 & $0 . \frac{-0.14}{000000}$ & $\underline{0.15}$ & $\underline{0.000000}$ & $\frac{-0.005}{0.000875}$ & 0.0 .006887 & $<0.0000000$ \\
\hline 500 & $0 . \frac{-0.10}{000006}$ & $\underline{0.11}$ & $\underline{\underline{0.74}}$ & $0 . \frac{-0.01}{000000}$ & 0.0 .0065887 & 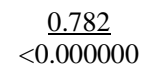 \\
\hline 550 & $0 . \frac{-0.06}{001175}$ & $\underline{0.04}$ & $\underline{0.000000}$ & $0 . \frac{-0.01}{000000}$ & 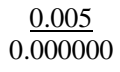 & $<0.0000000$ \\
\hline 579 & $0 . \frac{-0.036}{0.014427}$ & $0 . \frac{0.007}{041265}$ & 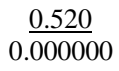 & $\frac{-0.008}{0.000000}$ & 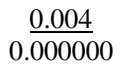 & 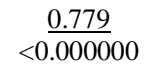 \\
\hline
\end{tabular}




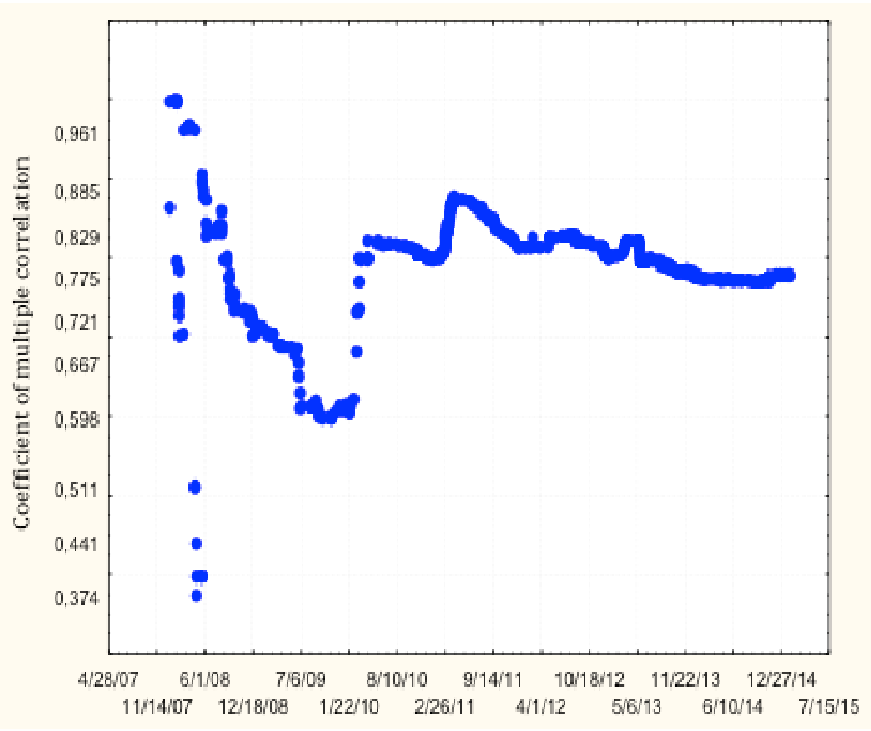

Fig.6. Change in values of coefficients of multiple correlation

TABLE III. COMPARISON OF AVERAGE VALUES OF INDICATORS

\begin{tabular}{|c|c|c|c|}
\hline \multirow[t]{2}{*}{ Indicators } & \multicolumn{2}{|c|}{ Statistical characteristics of indicators } & \multirow{2}{*}{$\begin{array}{c}\text { Criteria } \\
\frac{t_{-}}{p}\end{array}$} \\
\hline & Class 1 & Class 2 & \\
\hline $\mathrm{P}_{\mathrm{b}-\mathrm{h}}, \mathrm{MPa}$ & $6.5 \pm 1.5$ & $5.9 \pm 1.4$ & $\frac{3.79891}{0.000161}$ \\
\hline $\mathrm{H}_{\mathrm{d}}, \mathrm{m}$ & $1219.0 \pm 256.5$ & $1350.9 \pm 264.1$ & $\frac{-5.35565}{0.000000}$ \\
\hline $\mathrm{P}_{\mathrm{wh}}, \mathrm{MPa}$ & $1.55 \pm 0.67$ & $1.42 \pm 0.43$ & $\frac{2.30247}{0.021664}$ \\
\hline $\mathrm{W}, \%$ & $6.5 \pm 13.2$ & $14.7 \pm 19.7$ & $\frac{-5.66473}{0.000000}$ \\
\hline $\mathrm{Q}_{\mathrm{fl}}, \mathrm{m}^{3} /$ day & $7.8 \pm 10.6$ & $9.9 \pm 12.9$ & $\frac{-1.98733}{0.047358}$ \\
\hline $\mathrm{Q}_{\text {oil }}(\mathrm{t} / \mathrm{day})$ & $6.2 \pm 8.5$ & $6.2 \pm 8.5$ & $\frac{0.07263}{0.942123}$ \\
\hline $\mathrm{H}_{\mathrm{w}-\mathrm{o} \text { cont }}, \mathrm{m}$ & $1844.1 \pm 0.5$ & $1844.5 \pm 1.3$ & $\frac{-5.27533}{0.000000}$ \\
\hline $\mathrm{H}_{\text {pump }}, \mathrm{m}$ & $1585.8 \pm 51.7$ & $1596.1 \pm 79.1$ & $\frac{-1.79998}{0.072386}$ \\
\hline $\mathrm{H}_{\mathrm{subm}}, \mathrm{m}$ & $469.3 \pm 228.4$ & $405.9 \pm 182.6$ & $\frac{3.05555}{0.00235}$ \\
\hline
\end{tabular}

Sample division as per the time classes is taken into the account when formulating resultant regression equations.

In the first case, the regression equation is as follows:

$\mathrm{P}_{\mathrm{b}-\mathrm{h}}^{\mathrm{m} 1}=-2582.13-0.003 \mathrm{H}_{\mathrm{d}}+1.41 \mathrm{H}_{\mathrm{w}-\mathrm{ocont}}+0.03 \mathrm{~W}+$ $0.36 \mathrm{P}_{\mathrm{wh}}-0.14 \mathrm{Q}_{\mathrm{fl}}+0.15 \mathrm{Q}_{\text {oil }}-0.002 \mathrm{H}_{\text {pump }}$.

where $\mathrm{R}=0.797, \mathrm{p}<0.0000$, the standard error constitutes $0.91 \mathrm{MPa}$.

Model generation was provided in the succession, given in the regression equation. The coefficient values, defining force of statistical relations, changed as follows: $\mathrm{r}=0.563 ; \mathrm{R}=0.714$, $0.753,0.764,0.782,0.794,0.797$.

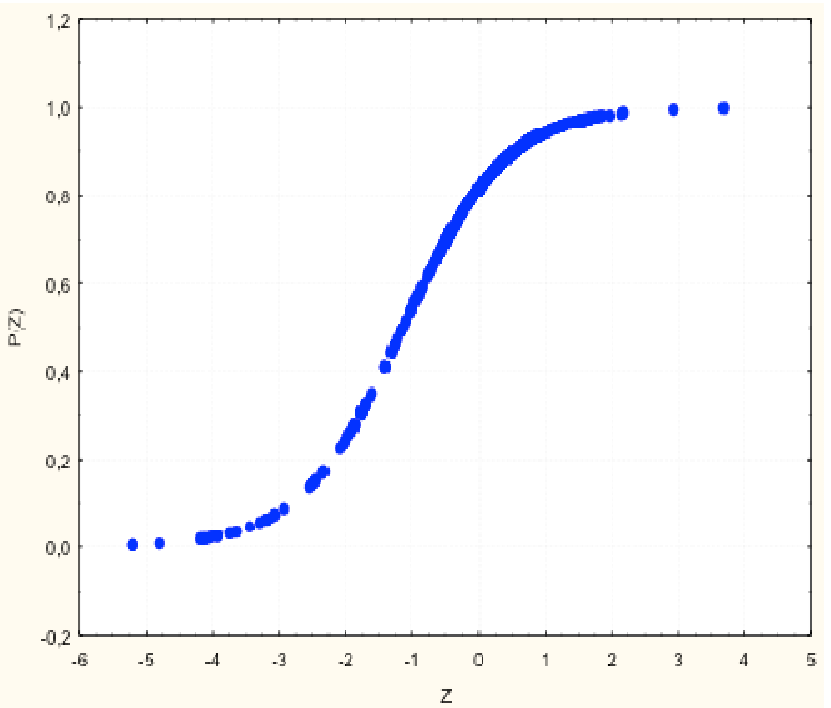

Fig. 7. The relationship between $P(Z)$ and $Z$

According to the given model values $\mathrm{P}_{\mathrm{b}-\mathrm{h}}{ }^{\mathrm{m} 1}$ were calculated as per the first class data.

In the second case, the regression equation is as follows: $\mathrm{P}_{\mathrm{b}-\mathrm{h}}^{\mathrm{m} 2}=-515.582+0.007 \mathrm{H}_{\text {subm }}-0.008 \mathrm{H}_{\text {pump }}-0.078 \mathrm{Q}_{\text {oil }}+$ $0.018 \mathrm{~W}+0.288 \mathrm{H}_{\mathrm{w}-\mathrm{o}-\mathrm{cont}}+0.705 \mathrm{P}_{\mathrm{wh}}+0.001 \mathrm{Hd}+0.016 \mathrm{Q}_{\mathrm{fl}}(6)$

where $\mathrm{R}=0.913, \mathrm{p}<0.0000$, the standard error constitutes $0.57 \mathrm{MPa}$.

Model generation was provided in the succession, given in the regression equation. The coefficient values, defining force of statistical relations changed as follows: $r=0,562, R=0,710$, $0.783,0.859,0.886,0.911,0.912,0.913$. According to the given model, values $\mathrm{P}_{\mathrm{b}-\mathrm{h}}{ }^{\mathrm{M} 2}$ were calculated as per the second class data.

Comparison of the actual and model (for two classes) values of the bottom-hole pressure is given in Fig. 8 .

Analysis of Fig. 4 exhibits that the actual and model values of bottom-hole pressure provide high accuracy control of each other.

To prevent gross errors while predicting bottom-hole pressure values, the model was built taking into the account both: values $\mathrm{P}_{\mathrm{b}-\mathrm{h}}{ }^{\mathrm{MO}}$ and values $\mathrm{P}_{\mathrm{b}-\mathrm{h}}{ }^{\mathrm{m} 1}, \mathrm{P}_{\mathrm{b}-\mathrm{h}}{ }^{\mathrm{m} 2}$ jointly being as follows:

$\mathrm{P}_{\mathrm{b}-\mathrm{h}}^{\mathrm{MM}}=3.927-0.9316 \mathrm{P}_{\mathrm{b}-\mathrm{h}}{ }^{\mathrm{MO}}+0,7115\left(\mathrm{P}_{\mathrm{b}-\mathrm{h}}{ }^{\mathrm{m} 1}, \mathrm{P}_{\mathrm{b}-\mathrm{h}}^{\mathrm{m} 2}\right)-0.0103\left(\mathrm{P}_{\mathrm{b}-}\right.$ $\left.{ }_{\mathrm{h}}^{\mathrm{MO}}\right)^{2}+0.1476 \mathrm{P}_{\mathrm{b}-\mathrm{h}}{ }^{\mathrm{MO}} *\left(\mathrm{P}_{\mathrm{b}-\mathrm{h}}{ }^{\mathrm{m} 1}, \mathrm{P}_{\mathrm{b}-\mathrm{h}}{ }_{\mathrm{m}}\right)-0.045\left(\mathrm{P}_{\mathrm{b}-\mathrm{h}}{ }^{\mathrm{m} 1}, \mathrm{P}_{\mathrm{b}-\mathrm{h}}{ }^{\mathrm{m} 2}\right)^{2}$,

where $\mathrm{R}=0.893, \mathrm{p}<0.0000$, the standard error constitutes $1.51 \mathrm{MPa}$.

Comparison of values $\mathrm{Pb}-\mathrm{h}$ and $\mathrm{Pb}-\mathrm{h}^{\mathrm{MM}}$ is demonstrated with regard to suitable correlation field (Fig.9).

The analysis of the given correlation field exhibits that the actual bottom-hole pressure values and the values of the bottom-hole pressure calculated, using the developed multidimensional model, control each other reliably enough with practically similar accuracy, regarding all the value range. 


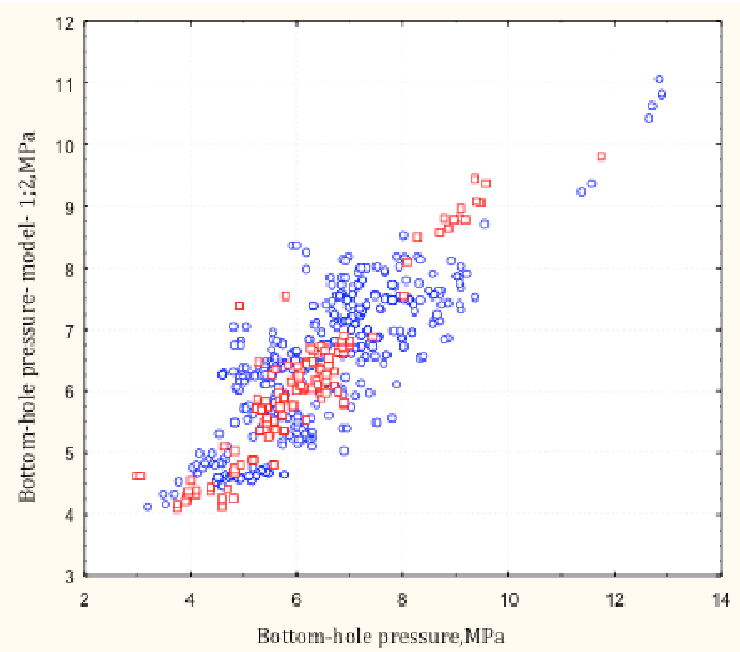

Fig.8. Comparison of actual and model (for two classes) values of bottomhole pressure

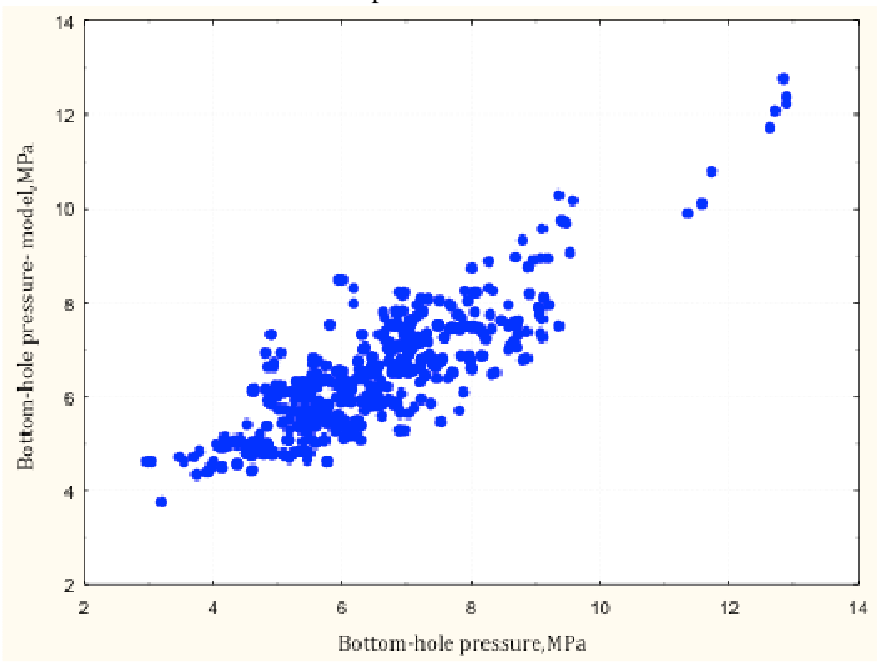

Fig.9. Correlation field between actual bottom-hole pressure and bottom-hole pressure calculated as per multidimensional model

\section{CONCLUSION}

1. A multidimensional mathematical model has been developed that allows determining the bottom-hole pressure according to known values of exploitation indices.

2. The advantage of the developed method for determining the bottom-hole pressure is the use as input parameters of only those parameters, the determination of which during well operation is not accompanied by significant difficulties.
3. The principal difference of this technique from previously known ones is the lack of separation of the wellbore into separate intervals, the absence of a stage of calculating the characteristics of a multiphase flow.

\section{References}

[1] A.M. Ansari et al., "A Comprehensive Mechanistic Model for TwoPhase Flow in Wellbores", SPE Production \& Facilities, vol.09, no.2, pp. 143-152, May 1994

[2] H.D. Beggs, J.P. Brill, "A Study of Two-Phase Flow in Inclined Pipes", Journal of Petroleum Technology, vol.25, no.05, pp. 607-617, May 1973.

[3] H.Jr. Duns, N.C.J. Ros, "Vertical Flow of Gas and Liquid Mixtures in Wells", Proc. 6th World Petroleum. Congress. Section II. Frankfurt am Main, 1963, pp. $451-465$.

[4] A. R. Hagedorn, K.E.Brown, "Experimental Study of Pressure Gradients Occurring During Continuous Two-Phase Flow in Small-Diameter Vertical Conduits", Journal of Petroleum Technology, vol.17, no.04, pp. 475-484, April 1965.

[5] A. R. Hasan, C. S. Kabir, «A Study of Multiphase Flow Behavior in Vertical Wells», SPE Prod. Eng., vol. 3, no. 02, pp. 263-272, May 1998.

[6] J. P. Brill, H. Mukherjee, «Multiphase Flow in Wells». Monograph 17, SPE. Richardson, Texas, Society of Petroleum Engineers Incorporated, $1999,384 \mathrm{p}$.

[7] J. Orkiszewski, "Predicting Two-Phase Pressure Drops in Vertical Pipes", Journal of Petroleum Technology, vol.19, no.6, pp. 829-838, June 1967.

[8] A. L.Podio, J. N. McCoy, D. Becker, «Integrated Well Performance and Analysis», SPE Computer Applications, June 1992, pp. 43-48. DOI: 10.2118/24060-PA.

[9] A. V. Lekomtsev, E.V. Zhelanov, I.A. Chernykh, "Statistical approach to the evaluation of bottomhole pressures in producing wells", Oil industry, No. 10, pp. 98-3101, 2016.

[10] I.A. Chernykh Determination of bottomhole pressure by using multivariate statistical models (on example of formation TL-BB Yurchukskoie field). Bulletin of PNRPU. Geology. Oil \& Gas Engineering \& Mining, vol.15, no.21, pp.320-328, 2016. DOI: 10.15593/2224-9923/2016.21.3

[11] I.S. Putilov, V.I. Galkin, «The results of statistical analysis for study fades characterization of T-Fm stage of Sibirskoe oilfield». Neftianoe khoziaistvo, no.9, pp.112-114, 2007.

[12] V.I. Galkin, I.N. Ponomareva, S.S.Cherepanov, «Development of the methodology for evaluation of possibilities to determine reservoir types based on pressure build-up curves, geological and reservoir properties of the formation (case study of famen deposits of ozernoe field)». Bulletin of PNRPU. Geology. Oil \& Gas Engineering \& Mining, 2015, no. 17, pp. 32-40. DOI: 10.15593/2224-9923/2015.17.4

[13] A.V. Shcherbenev, «Use of probabilistic and statistical methods for separation of rocks into permeable and impermeable parts (on example of clastic deposits of Visean stage of Sofyinskoe field)». Bulletin of PNRPU. Geology. Oil \& Gas Engineering \& Mining, 2017, vol.16, no.1, pp.14-22. DOI: $10.15593 / 2224-9923 / 2017.1 .2$ 